\title{
MIGRAÇÕES CONTEMPORÂNEAS, COMIDA E TRANSNACIONALISMOS A PARTIR DE UMA CIDADE GLOBAL ${ }^{1}$
}

\author{
Carla Pires Vieira da Rocha ${ }^{2}$
}

\begin{abstract}
Resumo: O texto aborda como os processos relacionados ao período atual da globalização se manifestam a partir de práticas voltadas à alimentação de imigrantes de diferentes nacionalidades no contexto da cidade de Amsterdã (Países Baixos). Resulta de uma pesquisa de doutorado de cunho etnográfico, com trabalho de campo realizado entre o mês de abril de 2015 a março de 2016, nessa capital. O foco da investigação recaiu sobretudo nas dimensões socioculturais do fenômeno alimentar e nos significados que a comida pode adquirir em uma condição migratória. Em paralelo, a atenção esteve voltada para especificidades das migrações contemporâneas, em especial no que diz respeito às dimensões culturais envolvidas e ao caráter essencialmente transnacional que têm demarcado muitos desses movimentos, repercutindo não apenas em como indivíduos desterritorializados vêm se relacionando com a comida, mas também em como estabelecem diferentes modalidades de conexões através da comida.
\end{abstract}

Palavras-chave: Migrações contemporâneas. Alimentação. Globalização. Transnacionalismos.

\begin{abstract}
The text addresses how the processes related to the current period of globalization are manifested from practices related to food of immigrants of different nationalities in the context of the city of Amsterdam (Netherlands). It results from a doctoral research of an ethnographic nature, with fieldwork carried out between the month of April 2015 and March 2016 , in this capital. The focus of the investigation was mainly on the sociocultural dimensions of the food phenomenon and on the meanings that food can acquire in a migratory condition. In parallel, attention was focused on the specificities of contemporary migrations, especially with regard to the cultural dimensions involved and the essentially transnational character that have demarcated many of these movements, reflecting not only how deterritorialized individuals have been relating to food, but also in how they establish different modalities of connections through food.
\end{abstract}

Keywords: Contemporary migrations. Food. Globalization. Transnationalisms.

Os movimentos migratórios integram a trajetória humana. $\mathrm{Na}$ contemporaneidade, ao mesmo tempo em que se ampliam, esses movimentos vêm se diversificando. Independente da motivação envolvida, tais deslocamentos não se resumem a uma mudança geográfica,

1 O presente trabalho foi realizado com apoio da Coordenação de Aperfeiçoamento de Pessoal de Nível Superior - Brasil (CAPES) - Código de Financiamento 001.

2 Doutora em Ciências Humanas pela Universidade Federal de Santa Catarina (UFSC). Pós-doutoranda no Programa Interdisciplinar em Ciências Humanas (UFSC) 
implicando uma reelaboração de diversos elementos que colaboram para dar sentido à vida cotidiana. Neste processo, a alimentação, uma vez que se situa num campo de interação entre a experiência no novo destino e aquela relacionada ao país de origem, pode consistir em um fator que contribui para se lidar de maneira mais positiva com uma nova realidade ou então ao contrário, isto é, pode representar um desafio a mais a ser enfrentado em um contexto de profundas mudanças.

A relação entre alimentação e migração não é algo novo. Migrantes são reconhecidos agentes na circulação transnacional de comidas que, ao carregarem consigo novos produtos e práticas alimentares, acabam interferindo em hábitos alimentares e padrões de consumo locais. Em sentido inverso, inevitavelmente, incorporam novas comidas e também novas práticas nesse âmbito. Como observam Nützenadel e Trentmann (2008), afora a maior variedade de suprimentos e mais ampla possibilidade de escolhas ligadas ao que ingerir, a migração alimentar exerce um papel fundamental tanto na redefinição de relações étnicas e identidades culturais como em representações nacionais.

Assim, como a comida vem ganhando progressivamente mais mobilidade num mercado global, o mesmo ocorre com os seus significados, embora estes sejam dependentes do contexto onde a comida circula. Quando se deslocam para um novo país, os indivíduos levam consigo hábitos, práticas e também ideias como referências para configurar seus estilos de vida, incluindo os relativos ao fenômeno alimentar ${ }^{3}$. Nessa esfera, hábitos e práticas podem ou não ter continuidade no local de destino. As permanências e as mudanças relacionadas à alimentação têm sido profundamente demarcadas pelos processos relacionados à globalização. Marcados pelo transnacionalismo, esses processos vêm facilitando um certo viver entre dois ou mais lugares ao mesmo tempo, se não fisicamente, ao menos por inúmeras formas de reprodução cultural, nas quais a comida constitui-se como um elemento fundamental.

No estágio atual da globalização, tanto o comportamento como diferentes práticas associadas à comida, sobretudo nos países desenvolvidos, vêm passando por uma crescente reconfiguração. Tal conjuntura inclui mudanças fundamentais a respeito de como e por que os alimentos são produzidos (ou não produzidos), os modos pelos quais são distribuídos (ou não distribuídos) e, variavelmente, preparados, ingeridos, compartilhados, pensados, imaginados, discutidos e disputados (INGLIS, GIMLIN, 2009). Além de ingredientes, a aceleração de fluxos

3 O estilo de vida é concebido como um conjunto de práticas sociais evocadas pelos indivíduos em suas rotinas diárias (SPAARGAREN, 2003), algo que também vai além do preenchimento de necessidades utilitárias, atuando ainda na constituição de identidades (GIDDENS, 2002). 
globais se estende a um universo mais amplo relativo à comida, incluindo livros de receitas, programas televisivos, sites sobre o tema na internet, cozinheiros, etc. Delinear esse horizonte é fundamental para se refletir sobre a alimentação em âmbito migratório, uma vez que a comida abarca aspectos que vão além da tomada alimentar. Hoje, em razão do aprimoramento das tecnologias informacionais e comunicacionais, outros fluxos são estabelecidos e potencializados em torno da comida, redimensionando não somente a maneira de nos relacionarmos com a alimentação, mas também a partir dela.

Este texto resulta de uma pesquisa de doutorado de cunho etnográfico direcionada para explorar como os processos relacionados à atual fase da globalização vêm ganhando expressão a partir das práticas voltadas à alimentação de imigrantes transnacionais na cidade de Amsterdã (Países Baixos) $^{4}$. O trabalho de campo foi realizado do mês de abril de 2015 a março de 2016 na cidade de Amsterdã. $O$ foco da investigação recaiu nas dimensões socioculturais do fenômeno alimentar. $\mathrm{O}$ tema da alimentação e migração já recebeu a atenção de diversas pesquisas acadêmicas, cuja abrangência envolveu os mais variados contextos nacionais. A maior parte desses estudos dedicou-se a um determinado grupo étnico. Nessa investigação, o olhar esteve voltado para indivíduos de diversas nacionalidades, buscando contemplar o caráter essencialmente transnacional das migrações em vigor.

\section{Globalização, migrações e transnacionalismos}

Os deslocamentos internacionais em vigor têm sido objeto de crescente atenção dada a sua diversidade, novos significados e implicações, em especial no que se refere aos seus vínculos com a globalização e decorrente intensificação dos processos transnacionais (SASSEN, 1998, 2010; GLICK et al. 1995; VERTOVEC, COHEN, 2006). O implemento tecnológico nas áreas da comunicação e transportes e o menor custo desses serviços e produtos, com relação a períodos anteriores, têm favorecido os deslocamentos atuais. Este painel também é visto pelas lentes da restruturação do capitalismo e, portanto, como determinante para a integração das diferentes partes do mundo num sistema único de produção, investimento, comunicação, coordenação, pessoal, produção e distribuição (SASSEN, 1998). A mesma fase ainda é associada a uma reelaboração de significado das fronteiras nacionais, no que tange à

4 Ver: ROCHA, Carla Pires Vieira da. Comida em uma cidade global: práticas alimentares de imigrantes transnacionais em Amsterdã. Tese (Doutorado Interdisciplinar em Ciências Humanas), Florianópolis, Universidade Federal de Santa Catarina, 2017. 
produção e distribuição de objetos, ideias, capital e pessoas (APPADURAI, 1990; GLICK et al, 1995; HANNERZ, 1997).

O número de migrantes internacionais quase triplicou durante as últimas cinco décadas: de 76 milhões em 1960 para 214 milhões em 2010. É no continente europeu que se concentra a maior parte dos migrantes internacionais (82 milhões). Segundo a Organização das Nações Unidas, entre os anos de 2013 e 2014, a soma de imigrantes internacionais ao redor do mundo esteve em torno de 232 milhões. Já no ano de 2019, este número atingiu cerca de 272 milhões, representado um aumento de 51 milhões desde $2010^{5}$. Hoje, o total representa 3,5\% da população mundial. Embora não pareça um percentual muito expressivo, tendo em vista o ritmo desse crescimento, a quantidade de migrantes internacionais estimada para o ano de 2050 é de 405 milhões, ou seja, mais que o dobro da soma atual.

Múltiplas abordagens visam dar conta dos processos potencializados nas últimas décadas associados à globalização, envolvendo mudanças em larga escala que vêm incidindo nas diferentes dimensões da experiência humana, incluindo os movimentos migratórios. Diversos autores atribuem o desencadear da globalização a períodos bem anteriores. Para Braudel (1986) e Wallerstein (1979), a conjuntura da globalização, respectivamente abordada a partir dos conceitos de economia-mundo e sistema-mundo, está intimamente relacionada ao desenvolvimento histórico do capitalismo, a partir do século XVI. Em paralelo, também se enfatiza o período relativo a meados do século XX, quando as inovações tecnológicas e comunicacionais operariam como forças motrizes para a articulação dos mercados e circulação do capital em escala mundial (GIDDENS, 2003; ORTIZ, 1994).

Ao discorrer sobre o tema, Beck (2008) igualmente acena para a multiplicidade de círculos sociais, redes de comunicação, relações de mercado e modos de vida que, sem vínculo com um lugar específico, transpassam as fronteiras territoriais dos Estados nacionais em todas as direções. Por sua vez, Sassen (2010) defende que, embora os processos globais transcendam o quadro dos Estados Nacionais, de modo simultâneo, ainda habitam parcialmente territórios e instituições nacionais. Em seu ponto de vista, a globalização vai além da interdependência crescente do mundo em geral e da formação de instituições globais, abrangendo dois conjuntos distintos de dinâmicas: o primeiro envolve a formação de processos e instituições explicitamente globais, ainda que ocorram em escala nacional. O segundo conjunto abarca processos não manifestados necessariamente em nível global, mas considerados integrantes da

5 Disponível: https://news.un.org/pt/story/2019/09/1687312 Acesso em: 14/10/21. 
globalização por incluírem redes e entidades transfronteiriças que conectam vários processos e atores locais ou nacionais, abarcando ainda a recorrência de questões ou dinâmicas específicas em um número cada vez maior de países ou localidades.

As especificidades dos deslocamentos atuais, demarcados pelo transnacionalismo, têm levado teóricos a conceberem as migrações como meios dos mais significativos pelos quais fronteiras e limites vêm sendo contestados e transgredidos (GLICK et al, 1995; KEARNEY, 1995). Como ressalta Glick et al. (1995), o novo estágio do capitalismo marcado pela reestruturação da produção, da distribuição, do consumo e da cultura alimentam as migrações internacionais e facilitam a manutenção de laços com os países de origem. Porém, a autora ainda ressalta que o transnacionalismo não é um processo novo, já que esses laços sempre estiveram presentes nas migrações internacionais desde fins do século XIX. Joppke e Morawska (2003, p. 20) reconhecem que embora não corresponda a um fenômeno novo na história das migrações internacionais, o transnacionalismo imigrante contemporâneo não é uma réplica exata do anterior, mas uma "configuração diferente de circunstâncias".

Assim como a intensificação de diferentes fluxos (ideias, imagens, pessoas, mercadorias, capital) vem configurando o período atual da globalização (APPADURAI, 1990, 1996, HANNERZ, 1997, 2014), o aprimoramento de conexões transnacionais entre grupos sociais também tem representado uma manifestação chave do mesmo processo (VERTOVEK, 2009). Tais conexões podem ser mantidas através de diversas formas: remessas de dinheiro e mercadorias, atividades de negócios, participação política, investimentos, viagens e também por meio da troca de ideias e comunicações.

É certo que a manutenção de qualquer forma de contato com a família e membros do país de origem (e mesmo com migrantes em demais destinos), sobretudo por correspondência ou o envio de remessas monetárias, não é novidade. Porém, como chamam a atenção Basch et al. (1994) e Vertovec (2009), na atualidade, a construção e manutenção de interconexões transnacionais são favorecidas por uma ordem distinta daquela mantida pelas migrações passadas, reiterando que o aumento na densidade, multiplicidade e importância de tais interconexões foi proporcionado e sustentado pelas transformações nas tecnologias de transporte e comunicação, cujos implemento e aprimoramento vêm facilitando progressivamente ligações mais próximas e imediatas com locais distantes.

Porém, como adverte Vertovec (2009), ainda que o quadro no qual o transnacionalismo desponta pareça sugerir, nem todos os imigrantes nos dias de hoje mantêm os referidos 
engajamentos sociais, políticos e econômicos para além de fronteiras nacionais. Como chama a atenção o autor, as formas de contato e trocas transnacionais, ademais de possivelmente seletivas e fluidas, dependem de uma gama de condições. Por essa razão, devem ser levados em conta fatores diversos que abrangem muitas variáveis, como as relativas à etapa de vida e o contexto nos quais os indivíduos se estabelecem.

Há numerosos caminhos para se contornar a globalização. Ainda que pontos de vista privilegiem os seus aspectos econômicos, existem outras dimensões igualmente relevantes, conforme sinalizam algumas das considerações acima. Como adverte King (1994), se nos atentarmos somente aos processos econômicos deste fenômeno, podemos subestimar os de resistência social e cultural, tanto em termos de escala como da força que possuem.

Portanto, o terreno cultural é um dos eixos representativos de como os processos globais operam e influenciam nas práticas sociais, entre as quais as relativas à alimentação. De maneira similar ao que ocorre em outras áreas, esses processos transcendem os estados nacionais, ganhando feição em um espaço global. Tal conjuntura também reflete um redimensionamento nos modos pelos quais o tempo e o espaço, coordenadas essenciais da vida social moderna, são experimentados e representados, uma vez que já não consistem em barreiras fixas ou intransponíveis a muitas formas de interação e organização social (GIDDENS, 2003). Em virtude da "compressão espaço-temporal", resultante da aceleração dos processos globais, temos cada vez mais de lidar com o impacto provocado pela aceleração do ritmo da vida e a sensação de que o mundo parece encolher sobre nós (HARVEY, 2004, p. 198-257).

Embora o escopo de análise ganhe diferentes enfoques e não haja uma definição única ou consenso com relação às consequências do período atual da globalização, muitos dos aspectos que vêm caracterizando esse fenômeno são incontestáveis. A intensificação das migrações internacionais é um desses aspectos. São diversas as motivações que têm desencadeado tais movimentos. A busca por um novo estilo de vida, baseado sobretudo na possibilidade de se explorar e vivenciar dimensões culturais relacionadas ao país de destino, tem consistido em um dessas motivações, conforme será abordado a seguir.

\section{Migrações por estilos de vida}

Em muitos casos, o movimento migratório é a concretização de um projeto de vida e mesmo a realização de um sonho. Todavia, a imigração é sem sombra de dúvidas uma perturbação, abarcando diferentes níveis de transformações na vida de indivíduos. Há uma 
gama de desafios a serem superados. Esses desafios incluem negociações envolvendo alteridade, como também ter de lidar com frustrações ligadas a estilos de vida idealizados, mas difíceis de se concretizar ou que tiveram de sofrer vários remodelamentos. Nessa perspectiva, a vida diária des sujeitos em tal condição pode ser concebida como resultado de uma constante negociação, frente à necessidade de conciliarem as experiências vividas na prática com suas expectativas e sonhos (BENSON, O'REALLY, 2009).

Essa ambiguidade entre expectativas e sonhos foi tomada como um ponto de partida para a abordagem de como indivíduos que se enquadram na categoria de imigrantes transnacionais vêm se relacionando com a comida na cidade de Amsterdã. Do mesmo modo que as migrações internacionais estão consignadas a variáveis diversas (econômicas, ambientais, políticas, culturais), o consumo alimentar, tanto no que tange à continuidade de hábitos alimentares como novas experiências ligada à comida, está atrelado às circunstâncias e possibilidades envolvidas em tal mobilidade, assim como ao contexto no qual ocorrem essas experiências ${ }^{6}$.

Os sujeitos que integraram a pesquisa em questão foram nove homens e catorze mulheres, com idades entre 21 e 54 anos, provenientes de diferentes países, incluindo alguns do continente sul-americano (Venezuela, Curaçao/Antilhas Holandesas, Jamaica, Brasil), e também países da Europa (Espanha, Portugal, Alemanha, França, Áustria, Suíça, Itália, Rússia) e da África (Costa do Marfim). Mais da metade dos sujeitos possuía formação universitária e quase o total da outra metade possuía curso de formação técnica. Salvo uma brasileira, todos os indivíduos entrevistados estavam em situação legalizada na Holanda. Desta forma, além de residir, podiam trabalhar no país e ainda ter garantidos muitos direitos. A distinção de temporalidades com relação ao período de permanência destes sujeitos em Amsterdã (4 meses a 27 anos) à data das entrevistas também permitiu depreender diferenças com relação às suas práticas associadas à alimentação ${ }^{7}$.

6 Amsterdã é a cidade mais populosa dos Países Baixos e é também a capital de um dos países com maior densidade populacional da Europa - (estimado em 500.4 habitantes por quilômetro quadrado, no ano de 2014) por exemplo, tem área total equivalente à Holanda, mas metade da sua população. De acordo com dados oficiais, em 01 de janeiro de 2016, Amsterdã contava com uma população estimada em 834.713 habitantes 12.441 a mais que em 2015. Desde 2008, o crescimento anual da população tem totalizado uma média de 11.000 pessoas. Esse número é devido ao maior índice de nascimentos (11.016, em 2015) com relação à baixa taxa de mortalidade. Além desses fatores, o aumento da população também está associado às imigrações na cidade. Em 2014, a migração líquida externa (ou seja, o número de pessoas do exterior que vieram para a cidade menos o número de pessoas que emigraram ao exterior a partir de Amsterdã) foi de 4.200. Um ano depois, esse índice aumentou para a cifra de 8.300 .

7 No que se refere à distinção temporal que definiria a migração como permanente, Torkington (2010) observa o quanto é problemática essa distinção, já que pode acontecer de imigrantes passarem muitos anos em um 
O emprego da categoria imigrantes transnacionais para referenciar os sujeitos da pesquisa teve como fim evidenciar aspectos de sua condição migratória potencializados pela atual conjuntura de globalização, demarcada por formas de contato e trocas que cada vez mais rompem fronteiras nacionais, conforme já indicado acima (BASCH et al., 1994; VERTOVEC, 2009). Em outras palavras, todos estes sujeitos mantinham formas de conexão com seus países de origem ou mesmo outros locais e não necessariamente por meio de remessas monetárias, mas sobretudo através de conexões de cunho comunicativo.

Esses indivíduos eram provindos predominantemente de camadas médias em seus países de origem. Isso significa que não eram ricos, no sentido econômico, mas também que sua mobilidade não era necessariamente resultado da pobreza ou de dificuldades econômicas. Embora o enfoque em camadas médias não tenha sido definido como premissa, e sim conduzido pelo próprio percurso investigativo, ele reflete uma das faces das migrações internacionais contemporâneas, especialmente em contextos definidos como cidade global, nos termos de Sassen (1998, 2010), como é o caso de Amsterdã ${ }^{8}$. Além disso, levando em conta as perspectivas desses sujeitos com relação aos seus movimentos migratórios, chamo a atenção para Ray (2004), quando observa que as camadas sociais médias são frequentemente protagonistas da globalização, uma vez que, mesmo face a pressões de ordens diversas em contexto migratório, têm mais recursos para resistir se optarem por fazê-lo.

Ainda é relevante mencionar que alguns desses indivíduos se moveram de países igualmente fortes no plano econômico (Alemanha, França, Suécia). Contudo, a maioria provinha de países com economias consideradas correlativamente mais fracas, tanto dentro do continente europeu como fora (Venezuela, Brasil, Espanha, Costa do Marfim, Portugal, etc.). Ainda que o fator econômico não tenha sido apontado como motivo principal da emigração, para alguns, viver em Amsterdã não deixou de significar ascenderem socioeconomicamente; para outros, ao contrário, implicou se sujeitarem a novas condições de vida, compartilhando moradia com desconhecidos, trabalhando em funções muito aquém das suas habilidades

lugar sem fazer qualquer tentativa de resolver a situação migratória. Por essa razão, alguns sociólogos e geógrafos teriam adotado a designação de residência, considerando ser menos carregada emocionalmente.

8 Sassen (2010) utiliza a noção de cidade global referindo-se a cidades que se constituem como polos importantes de globalização da economia, onde múltiplos processos de âmbito global assumem formas concretas e localizadas, isto é, cidades mais facilmente acessíveis por meio das finanças (dinheiro), comunicações (viagens) e informação (radiodifusão, publicações, mídia). Além disso, de acordo com essa autora, o caráter internacional das cidades globais não está associado apenas à sua infraestrutura de telecomunicações ou empresas internacionais, mas também aos muitos ambientes culturais onde seus trabalhadores circulam. 
profissionais e ainda restringir suas práticas de consumo (incluídas as relacionadas à alimentação), entre outras situações consideradas limitadoras. Essas situações reportam às ponderações de Sassen (2010), quando observa que a racionalidade das migrações é algo complexo, existindo uma subjetividade envolvida como variável, de maneira que não se pode reduzir esses movimentos a fatores de repulsão (pobreza e desemprego) ou atração (possibilidades de emprego e melhores salários).

Apesar de pertencerem a camadas médias em seus países de origem, nem todos os sujeitos em questão se deslocaram nas mesmas condições. Um imigrante de Portugal (34 anos), por exemplo, se considerava pertencente à classe média quando vivia no país natal. Ambos os pais eram funcionários públicos, o que lhe garantiu uma série de oportunidades durante uma parte significativa de sua vida. No entanto, quando emigrou para Amsterdã, percebeu que sua condição de classe média nos últimos anos em Portugal estava muito abaixo do que a definia anteriormente naquele país e, em particular, com relação a essa mesma camada na Holanda. Prover o próprio sustento, ter melhores condições de trabalho ou lazer, como ocorre no presente, são situações que considerava improváveis na conjuntura do país natal no momento em que emigrou. Em seu ponto de vista, em decorrência da crise econômica em Portugal, a classe média estaria morrendo, restando somente um fosso muito grande entre a pobreza e a riqueza. Levando isso em conta, em Amsterdã, além de considerar não ter perdido qualidade de vida, concebia estar caminhando em direção a um estilo de vida compatível com as camadas médias em Amsterdã, já que agora conseguia novamente manter uma padrão de vida que, havia anos, não vinha sendo possível em seu país natal.

Mais da metade desses indivíduos emigrou para a cidade com um projeto migratório individualizado, envolvendo principalmente questões laborais. A noção de projeto migratório é concebida neste texto como um projeto de vida, nos termos de Velho (2003), algo que prevê um tempo de permanência na cidade, ainda que sujeito a reelaborações ${ }^{9}$. Hoje, dentro da Europa, conforme já acenado, Amsterdã é considerada um dos locais mais privilegiados no âmbito laboral. No entanto, estudo, turismo, fatores culturais ou mesmo questões afetivas também foram apontados como motivos para desencadearem tais deslocamentos e a decisão de permanecer na cidade aconteceu em um período posterior, sem necessariamente um planejamento prévio. Além disso, para alguns desses sujeitos, a emigração para esta capital implicou a continuidade de uma experiência migratória anterior em um ou mais países.

9 Para Velho (2003, p. 101), o projeto de vida é visto como o estabelecimento de objetivos e fins, assim como a organização dos meios através dos quais se constrói a trajetória e a biografia. 
A partir das entrevistas realizadas, foi possível perceber que a escolha de Amsterdã como destino também envolvia representações a respeito da cidade e mesmo algumas relativas ao próprio movimento migratório. Mas o fato de que alguns desses indivíduos tinham chegado à cidade havia vinte cinco anos ou dos que tinham chegado em datas mais recentes, indubitavelmente colocou em cena perspectivas diversas com relação à capital holandesa e correlativas às suas histórias de vida, as quais eram bastante distintas, uma vez que também englobavam a realidade de seus países de origem, sobretudo no período de emigração. Por mais condicionadas que as percepções da cidade estivessem à realidade anterior de cada um desses indivíduos e, não obstante Amsterdã também estar imersa em uma dinâmica de mudanças, esta cidade nutria alguns de seus imaginários reafirmados constantemente que a identificavam, acima de tudo, como um local de tolerância, liberdade e diversidade cultural. Tais qualidades atribuídas a esse centro urbano também colaboravam para que esses indivíduos alimentassem certas expectativas com relação à concretização de seus projetos de vida nesse contexto.

Todavia, ao se confrontarem com determinadas realidades, parte desses indivíduos viuse forçada a rever seus planos ou empreender esforços no sentido de conciliar seus projetos idealizados com a realidade que se apresentava. Um exemplo significativo refere-se à esfera profissional; mesmo entre aqueles com formação universitária, houve situações nas quais tiveram de reformular suas condições de vida, de acordo com as exigências envolvidas nas ofertas de trabalho. A falta de domínio do idioma holandês (quando pré-requisito), a indocumentação (mesmo que temporária) ou mesmo a escassez de oferta nas suas áreas de atuação, por exemplo, consistiram em motivos para abraçarem empregos temporários, de menor qualificação exigida e não tão vantajosos do ponto de vista financeiro, como serviços de limpeza, telemarketing, atendimentos em restaurantes ou pequenos comércios.

Conforme relatado nas entrevistas realizadas, apesar de muitas ofertas de trabalho em Amsterdã não exigirem rigorosamente que se domine o neerlandês (idioma holandês), bastando o inglês, há situações em que a dificuldade a ser enfrentada com relação àquele mercado de trabalho está relacionada ao fato de indivíduos migrantes estarem muito acima das qualificações exigidas para uma determinada vaga (overqualified). À vista disso, ainda que se sujeitassem a um trabalho para o qual não era dada a chance de colocarem em prática suas habilidades profissionais, mesmo assim não são considerados habilitados para tal. 
Outro ponto a ser destacado é que, embora Amsterdã tenha uma longa trajetória como destino migratório ${ }^{10}$, a receptividade a imigrantes neste contexto também vem sofrendo modificações. Apesar do reconhecimento da já mencionada tolerância social dos Países Baixos, inclusive no que se refere às políticas migratórias, especialmente no período posterior ao atentado às torres gêmeas em Nova York (EUA), no ano de 2001, esse quadro começou a passar por modificações. Os dois ataques terroristas em Paris no ano de 2015 (o primeiro na sede do jornal Charles Hebdo e o segundo, em diferentes locais da cidade simultaneamente) e os demais em Bruxelas, Istambul, Nice e Berlim, em 2016, vêm colaborando para acirrar as referidas modificações.

Além disso, ao longo dos últimos anos, Amsterdã tem passado por uma série de mudanças que também podem ser atribuídas à intensificação de fluxos de naturezas diversas na cidade, incluindo a diversificação de migrantes e ainda a potencialização do turismo. Em razão desses fluxos, aponta-se problemas que abrangem desde a dificuldade de se conseguir moradias com valores acessíveis até o aumento de impactos ambientais. Mesmo assim, a maioria dos indivíduos entrevistados ainda considera esse centro urbano como um local diferenciado positivamente em muitos aspectos para estabelecerem seus projetos de vida, o que pode justificar os deslocamentos migratórios vultosos para essa capital.

O deslocamento dos indivíduos que integraram a investigação não pode ser enquadrado de maneira integral no que Benson e O'Really (2009) concebem como migrações por estilos de vida, enquanto categoria de mobilidade em que a busca por qualidade de vida se sobrepõe a outros fatores. Contudo, tanto em conversas informais quanto nas entrevistas, algumas características dessa modalidade migratória puderam ser identificadas, possibilitando depreender que a busca por um estilo de vida melhor ou uma de vida boa, de certo modo, também estava presente no projeto migratório idealizado por esses indivíduos. Nesta perspectiva, destacamos o fato dessa modalidade de deslocamento não ter necessariamente relação com questões econômicas e também não indicar uma aventura; o que parece vigorar é a autorrealização como meta ou então a possibilidade de se encontrar o verdadeiro eu, tomando as experiências culturais como um dos aportes importantes em tal sentido (BENSON,

10 Amsterdã é considerada uma porta de entrada de imigrantes e tem uma longa história como destino migratório de indivíduos das mais diversas proveniências. A cidade também conta com um grande número de residentes nascidos no exterior $(28,2$ por cento). De acordo com dados oficiais, computando imigrantes de primeira e segunda geração, cerca de 178 nacionalidades estariam ali representadas. Dados estatísticos municipais de 2014 revelam que o total dessas populações 4445 (411.092) chega a ser superior ao número de holandeses (400.093). Devido à imigração em larga escala proveniente principalmente do Suriname, Marrocos e Turquia, há uma estimativa de que, em poucos anos, pessoas de origem não-europeia se tornarão o grupo étnico dominante em Amsterdã 
O'REALLY, 2009) ${ }^{11}$. No caso dos sujeitos entrevistados, cabe observar que a comida foi referida de modo recorrente como possibilidade de experiência cultural que norteou seus movimentos de migração, o que também pode ser interpretado como a busca de satisfação de seus anseios cosmopolitas ${ }^{12}$.

Portanto, ainda que a busca de trabalho tenha sido apontada pela maior parte dos sujeitos como motivação principal, tais deslocamentos também envolveram uma certa idealização do novo contexto - no caso Amsterdã - como local possível para materializarem determinadas expectativas e sonhos, especialmente no que se refere a experiências culturais. Para alguns destes sujeitos, a concepção mesma de emigração como movimento em busca de experiências culturais se converteu num ideal de estilo de vida. Além disso, à época da pesquisa, apesar da maior parte desses indivíduos não considerar o deslocamento para viver em outra cidade holandesa ou mesmo um outro país a curto prazo, para alguns, Amsterdã não era imaginada como destino final e sim um caminho até uma nova experiência migratória. Neste viés, os movimentos desses sujeitos ainda recaiu sobre a concepção de migração como um processo não necessariamente negativo e dramático, mas também como possibilidade de se construir novas

11 As autoras consideram que a migração por estilo de vida não é claramente motivada por dificuldades econômicas, pela procura de trabalho ou mesmo pela busca de alguma forma de segurança financeira. $\mathrm{Na}$ mesma concepção, os migrantes por estilo de vida não são parte dos fluxos transnacionais de elites empresariais ou intelectuais. Além disso, segundo as mesmas autoras, a busca pela qualidade de vida a partir destes deslocamentos é geralmente associada a vantagens materiais, como menor custo de vida ou então benefícios mais intangíveis como um clima mais ameno, uma dieta melhor e mais saudável, um ritmo de vida mais lento ou mais oportunidades de lazer (BENSON, O'REILLY, 2009).

12 Ao abordarem uma perspectiva de cosmopolitismo, Appadurai e Breckenridge (1988) notam que o mundo de hoje é cada vez mais cosmopolita e afora a maior abrangência de gostos e cozinhas a serem consumidos, cresce o número de pessoas que estão atentas a notícias em todo o mundo e expostas a eventos globais cobertos pela mídia ou que são ainda influenciadas por outras tendências universais. Nessa mesma linha de pensamento, Appiah (2006) chama a atenção para o fato de que pessoas, mesmo enraizadas em locais específicos, estão interagindo com o mundo cosmopolita da migração, nomadismo e diáspora. As contribuições de Vertovec (2002) são relevantes, sobretudo ao defender a compreensão do cosmopolitismo como de viés múltiplo e não algo restrito somente a indivíduos de classe alta e da cultura ocidental, mas também àqueles outros, cujas vozes desempenham um papel na produção de espaços cosmopolitas. Para tanto, faz referência à teoria do cosmopolitismo realmente existente de Robbins (1998), a qual propõe que se reconheça a existência de cosmopolitismos entre uma ampla variedade de não-elites, especialmente imigrantes. Segundo Vertovec (2002), teses de que o cosmopolitismo estaria disponível apenas para uma elite ou por quem tem recursos necessários para viajar, aprender outras línguas e absorver outras culturas repercutem em ataques frequentes a este conceito. Ainda que não discorde totalmente de argumentos nesse sentido, sobretudo no que diz respeito a uma grande maioria para quem o cosmopolitismo nunca foi uma opção, Vertovec (2009) reporta ao pensamento de Poole (1999) a fim de ressaltar que, no mundo contemporâneo, a diversidade cultural e linguística têm sido onipresentes e a capacidade de comunicar com os outros e entender suas culturas está disponível, pelo menos potencialmente, para muitos. Já Hannerz (1990) explora o cosmopolitismo como um estado de espírito, uma orientação que implica vontade de interagir com o Outro, um querer mergulhar em outras culturas ou ser livre para fazê-lo. Hannerz (1990) defende a emergência de uma cultura mundial, embora esta não signifique uma replicação da uniformidade, e sim a organização da diversidade, a crescente interconectividade das culturas locais variadas e também o desenvolvimento de culturas, embora sem uma ancoragem clara em qualquer território. Em sua tese, o cosmopolitismo consiste em uma das maneiras pelas quais os indivíduos se relacionam com essa diversidade. 
subjetividades (VAILATI, RIAL, 2016). Em tal perspectiva, as conexões sociais e comunicativas ganham destaque.

\section{Comida, comunicação e conexões transnacionais}

[...] deve-se falar, sobretudo, de gente que migra ou viaja, que não vive onde nasceu, que troca bens e mensagens com outra pessoas distantes, que assiste a cinema e televisão de outros países ou conta histórias em grupo sobre o país que deixou. Gente que se reúne para celebrar alguma coisa distante ou que se comunica por correio eletrônico com outras pessoas que não sabe quando irá rever. De certo modo, sua vida está em outro lugar. (CANCLINI, 2007, p. 46).

No universo migratório, as comidas circulam em malas, contêineres e também cada vez mais através de imagens. Por meio das tecnologias digitais, a comunicação em torno da comida vem ganhando proporções inéditas. Mas não apenas isso; é possível afirmar que a Internet vem mudando a maneira pela qual falamos, aprendemos, pensamos e também nos comunicamos a partir da comida. Neste panorama, emergem outros parâmetros para se refletir sobre o que vem engendrando a relação entre alimentação e migração, sob a perspectiva da globalização vigente.

As tecnologias da comunicação, por meio da Internet, vêm permitindo que indivíduos compartilhem seu cotidiano, seja através de textos, audios ou imagens, em tempo real e a partir de territórios, muitas vezes, absolutamente distantes. Ressaltando o papel cada vez mais presente e inelutável dessas tecnologias, Miller et al. (2016) observam que o virtual não deve ser concebido como um mundo on-line à parte, mas como algo integrante da vida cotidiana que devemos olhar da mesma maneira pela qual agora concebemos o lugar da conversa telefônica, isto é, como uma esfera integrada à nossa vida e não como algo separado. Nas entrevistas realizadas em Amsterdã, Skype e Whatsapp foram os dois serviços de comunicação via Internet de utilização regular referidos por imigrantes, sobretudo com familiares e o círculo de pessoas mais próximas. Já o Facebook foi apontado por alguns desses indivíduos como ferramenta de comunicação também com um universo social mais amplo.

Ao abordar o tema das tecnologias da comunicação em contexto migratório, Vertovec (2009, p. 14-15) chama a atenção para os novos potenciais associados ao desenvolvimento dessas tecnologias no panorama atual, ao permitirem uma comunicação contínua e em tempo real entre as redes globais de migrantes, e observa que tanto migrantes contemporâneos como processos de migração, ao mesmo tempo em que vêm se tornando dependendes dessa 
modalidade de interconectividade entre pessoas e sociedades ao redor do mundo, têm contribuído para o seu aumento. Reportando ao pensamento do sociólogo Manuel Castells, Vertovec (2009, p. 05) ainda observa que tais tecnologias "estão no coração das redes transnacionais de hoje", mas também lembra que, se o aprimoramento das conexões transnacionais entre grupos sociais é uma manifestação chave da globalização, não se deve perder de vista que as tecnologias não criam novos padrões sociais, apenas reforçam aqueles pré-existentes.

A comunicação em torno da comida através das mídias de relatada por imigrantes em Amsterdã também revelou um outro aspecto da incidência dos processos globais na alimentação, ou seja, como a mobilização de pessoas e ideias vêm contribuindo para que imaginários relacionados à globalização sejam nutridos através da comida. Como chama a atenção Phillips (2006), trabalhadores migrantes, refugiados, populações realocadas, imigrantes, estudantes, turistas e demais viajantes teriam um papel importante na reprodução e expansão de ideias sobre alimentação e sistemas alimentares, ainda que nem todos na mesma extensão ou de igual maneira.

Portanto, nesse mesmo panorama, onde também se disseminam outros fluxos culturais ligados à comida, a difusão de imagens, ideias ou práticas relacionadas a este tema, ainda pode revelar como indivíduos desterritorializados vêm se relacionando a partir da comida e a heterogeneidade de significados atribuídos à alimentação a partir de um determinado contexto. No caso dos sujeitos pesquisados, inseridos na dinâmica global da cidade de Amsterdã, estes indivíduos quando também fotografavam ou compartilhavam imagens de comidas ou de ideias relacionadas ao que comiam a partir das mídias sociais, comunicavam sua experiência migratória, o que também implicava uma atribuição de sentido por parte de cada um deles, especialmente no que se refere a viver em um outro país.

Mas a utilização das tecnologias da comunicação por imigrantes, além de não se resumir às mídias sociais, vêm exercendo um papel cada vez mais expressivo na maneira pela qual muitos indivíduos vêm gerindo suas práticas alimentares em condição migratória. Onde encontrar determinados produtos alimentares, como reproduzir algumas receitas, onde comer certas comidas, quais trajetos percorrer a fim de encontrar comércios específicos de alimentos, quais os valores nutritivos de alguns produtos alimentares. Essas foram algumas das questões relacionadas à alimentação relatadas por imigrantes em Amsterdã, recorrentes em seu cotidiano, para as quais, a utilização das tecnologias da comunicação foi considerada um fator-chave, 
possibilitando gerenciarem sua alimentação de modo mais eficiente, sobretudo para aqueles indivíduos que estavam em uma etapa de permanência mais recente na cidade ${ }^{13}$.

Certamente, para se avaliar em que medida e como essas tecnologias ressoam nestes deslocamentos, há que se considerar o contexto migratório, bem como o acesso a essas tecnologias por parte destes indivíduos. Portanto, é importante mencionar que todos os imigrantes entrevistados mantinham acesso regular à internet, principalmente através de aparelhos de telefonia móvel e computadores pessoais. Em Amsterdã, a exemplo de outros países desenvolvidos, o acesso à rede sem fio é bastante facilitado. Pode-se, por exemplo, comprar um cartão pré-pago para um aparelho móvel, destinado somente ao acesso à internet por um valor, que à data da pesquisa, era considerado relativamente baixo por parte desses indivíduos (cerca de 10 euros a recarga mensal). Além disso, muitos estabelecimentos públicos como supermercados, redes de comida rápida, restaurantes, cafés, lojas, museus, ônibus, entre outros locais, disponibilizam a rede sem fio de forma gratuita em seus recintos.

Sob o ponto de vista da comida, consideramos que um dos pontos relevantes para se pensar sobre a dinâmica global dos fluxos informacionais e seu papel nas migrações internacionais vigentes tem relação sobretudo com noções de autonomia associadas à maneira de indivíduos gerirem seus estilos de vida. Em épocas anteriores, dependia-se principalmente de redes sociais de outra natureza (familiares, amigos) já estabelecidas no país de destino para que se viabilizassem de maneira mais ágil práticas cotidianas incluindo as alimentares (o acesso a certos comércios ou serviços, por exemplo). Tais redes muitas vezes eram determinantes inclusive no que tange à implementação de projetos migratórios, já que muitas migrações somente se configuraram porque estas já estavam estabelecidas no países de destino. Através dessas redes,é facilitada sobretudo a circulação de informações e o compartilhamento de experiências, conectando lugares de origem e de destino, mas também tornando possível a recriação de espaços sociais a partir dos países de destino (MASSEY et al. 1993; TRUZZI, 2008).

13 O seguinte relato de uma imigrante que vivia há dezessete anos em Amsterdã mostra o quanto não dominar o idioma do país pode repercutir no consumo alimentar: Muitas vezes aconteceu de eu trazer coisas para casa que eram totalmente diferentes do que eu tinha pensado que eram quando comprei [...]. Ai chegava em casa e pensava que não era o que eu precisava, o que eu havia pensado. Isso era meio frustrante [...]. No início, eu tentava seguir minha dieta comum, mas o fato de que você não pode ler o rótulo dos produtos, você tem um problema a mais [...]. Você sai em busca de um produto especifico porque você quer fazer uma determinada coisa, você olha o rótulo e diz: ah, é isso! Mas quando você vê em casa alguma coisa diferente [...]. Então este é um desafio. Eu penso que se você não consegue ler os rótulos ainda é um grande problema para a sua nutrição. 
Portanto, embora as redes sociais convencionais ainda hoje vigorem como determinantes para muitos movimentos migratórios, não se pode ignorar a emergência dessas outras redes estabelecidas a partir do universo virtual e seu impacto em vários aspectos dos deslocamentos migratórios. Além disso, os fluxos globais ligados à comunicação vêm ampliando o leque de possibilidades e proporcionando novas maneiras de se lidar com a alimentação em contexto migratório, o que também acaba ressoando na maneira destes indivíduos estabelecerem seus projetos de vida na cidade em questão.

\section{Considerações finais}

O enfoque na relação entre alimentação e migração, sob o prisma da aceleração dos fluxos globais, é uma possibilidade de rever práticas relacionadas à natureza dinâmica e sujeita a constantes mudanças do fenômeno alimentar, alinhadas com processos transnacionais e, dessa forma, contribuir para contornar ao menos parte da complexidade desse fenômeno conjugado às imigrações em nossos dias. Como nos lembra Sidney Mintz (2001), a comida não se resume ao seu caráter fisiológico, constituindo-se também em um meio de nos relacionarmos com a realidade.

Em paralelo aos movimentos transfronteiriços de tecnologias, mercadorias, capital, os fluxos de pessoas se constituem em uma das questões-chave da globalização vigente. Nos dias de hoje, os movimentos humanos têm sido provocados por pressões relativas sobretudo a questões sociais, ambientais, políticas ou econômicas. Mas, nessa mesma conjuntura, deslocamentos com grande ênfase em suas dimensões culturais também se multiplicam, refletindo o caráter cada vez mais heterogêneo desses movimentos. Em tal perspectiva, vigora a ideia de migração como possibilidade de se vivenciar e explorar aspectos culturais relacionados ao país de destino, no que se inclui a alimentação.

Em tal perspectiva, a comida revela-se um elemento importante. Situada na intersecção entre o país de origem e o país de destino, abarcando mudanças e permanências, a alimentação torna-se um elo significativo para a compreensão de como a desterritorialização decorrente dos processos globais vem se expressando no contexto das migrações internacionais contemporâneas.

A partir do enfoque nas práticas alimentares de imigrantes transnacionais na cidade de Amsterdã, foi possível perceber ainda como fluxos informacionais e comunicacionais que se desenvolvem em torno da comida também têm constituído o cotidiano de indivíduos em tal 
condição de deslocamento. Voltar a atenção para como esses fluxos vêm ganhando expressão em experiências migratórias distintas possibilita contemplar uma perspectiva também importante para compreender a maneira pela qual os processos globais incidem na sua alimentação, como se expressam na configuração de seus estilos de vida no país de destino e, paralelamente, em que medida contribuem para potencializar o caráter transnacional desses movimentos.

\section{Referências Bibliográficas}

APPADURAI, A. Disjuncture and Difference in the Global Cultural Economy. In: WILLIAMS, P., CHRISMAN, L. Colonial Discourse and Post-Colonial Theory. N.Y.: Columbia University Press, 1990. p. 324- 339.

. Modernity at large: cultural dimensions of globalization. Minneapolis, Minn.: University of Minnesota Press, 1996.

APPADURAI, A.; BRECKENRIDGE, C. Why Public Culture? Public Culture, v. 1, n. 1, p. 59, 1988.

APPIAH, K. A. Cosmopolitanism: ethics in a world of strangers. New York: W. W. Norton \& Co, 2006.

BASCH, L. et al. Nations unbound: transnational projects and the deterritorialized nations-state. New York: Gordon and Breach, 1994.

BECK, U. Qué es la globalización?: falacias del globalismo, respuestas a la globalización. Barcelona: Paidós, 2008.

BENSON, M; O'REILLY, K. Migration and the search for a better way of life: a critical exploration of lifestyle migration. The Sociological Review, v. 57, n. 4, p. 608-625, 2009.

BRAUDEL, F. A dinâmica do capitalismo. 2 ed. Lisboa: Editorial Teorema, 1986.

CANCLINI, N. G. A globalização Imaginada. São Paulo: Iluminuras, 2007.

GIDDENS, A. A trajetória do eu. In: Modernidade e identidade. Rio de Janeiro: Jorge Zahar, 2002. p. 70-104.

. Mundo em descontrole: o que a globalização está fazendo de nós. 3 ed. Rio de Janeiro: Record, 2003.

GLICK, N. et al. From Immigrant to Transmigrant: Theorizing Transnacional Migration. Anthropological Quarterly, v. 68, n. 1, p. 48-63, Jan. 1995.

HANNERZ, U. Transnational Connections. Culture, People and Places. Londres: SAGE, 1990. p. 237-251. Disponível em: http://tcs.sagepub.com Acesso em: fev. 2014.

Fluxos, fronteiras, híbridos: palavras-chave da antropologia transnacional. Rio de Janeiro: Mana, v. 3, n. 1, abr. 1997. Disponível em: $<$ http://www.scielo.br/scielo.php?script=sci_arttext\&pid=S010493131997000100001\&lng=en\&nrm=iso>. Acesso em: 15 jan. 2015 . http://dx.doi.org/10.1590/S0104-93131997000100001. 2015. 
HARVEY, D. Condição pós-moderna. São Paulo: Loyola, 2004.

INGLIS, D., GIMLIN, I. Food globalizations: ironies ans ambivalences of food, cuisine and globality. In: . The globalization of food. New York: Berg, 2010. p. 3-42.

JOPPKE, C.; MORAWSKA E. Integrating immigrants in liberal nation-states: Policies and practices. In: (eds.). Toward Assimilation and Citizenship: Immigration in Liberal Nation-States. Basingstoke: Palgrave Macmillan, 2003. p. 1-36.

KEARNEY. The Local and the Global: The Anthropology of Globalization and Transnationalism. Annual Review of Anthropology, v. 24, p. 547-565, 1995.

KING, A. A arquitetura, o capital e a globalização da cultura. In: FEATHERSTONE, M. (coord.). Cultura global: nacionalismo, globalização e modernidade. Petrópolis: Vozes, 1994. p. 421-437.

MASSEY, D. et al. Theories of International Migration: A Review and Appraisal. Population and Development Review, v. 19, n. 3, p. 431-466, 1993.

MILLER, D. et al. How the world changed social media. London: UCLPRESS, 2016. Disponível em: http://discovery.ucl.ac.uk/1474805/1/How-the-World-Changed- SocialMedia.pd Acesso em: dez. 2016.

MINTZ, Sidney. Comida e Antropologia: uma breve revisão. RBCS, v. n. 2001.

NUTZENADEL, A.; TRENTMANN, F. Food and Globalization: Consumption, Markets and the Politics of the Modern World. Oxford: Berg, 2008.

ORTIZ, R. Mundialização e cultura. 2 ed. São Paulo: Brasiliense, 1994.

OSTENDORF, W.; FORTIJN, D. Amsterdam: gender and poverty. In: MUSTARD, S.; MURIE, A.; KESTELOOT, C. (eds.). Neighbourhoods of Poverty: Urban Social Exclusion and Integration in Europe. New York: Palgran Macmillan, 2006. p. 52-66.

PHILLIPS, L. Food and globalization. Annual Review of Anthropology. v. 35, p.37-57. 2006.

POOLE, R. Nation and Identity. London: Routledge, 1999.

RAY, K. The migrant's table: meals and memories in Bengali-American households. Philadelphia: Temple University Press, 2004.

ROBBINS, B. Introduction Part I: Actually existing cosmopolitanism. In: CHEAH, P.; ROBBINS, B. (eds.). Cosmopolitics. Minneapolis: University of Minnesota Press, 1998. p. 119.

ROCHA, C. P. V. Comida em uma cidade global: práticas alimentares de imigrantes transnacionais em Amsterdã. Tese (Doutorado Interdisciplinar em Ciências Humanas), Florianópolis, Universidade Federal de Santa Catarina, 2017.

SASSEN, S. As cidades na economia mundial. São Paulo: Nobel, 1998.

. Sociologia da globalização. Porto Alegre: Artmed, 2010.

SPAARGAREN, G. Sustainable consumption: a theoretical and environmental policy perspective. Society and Natural Resources, v. 16, p. 687-701, 2003. 
TORKINGTON, K. Defining lifestyle migration. Dos Algarves, n. 19. Revista da ESGHT/UAIg, 2010.

TRUZZI, O. M. S. Redes em processos migratórios. Tempo Social - Revista de Sociologia da USP, v. 20, p. 199-218, 2008.

VAILATI, A.; RIAL, C. Migration of rich immigrants: gender, ethnicity and class. London: Palgrove MacMillan, 2016.

VELHO, G. Projeto e metamorfose: antropologia das sociedades complexas. 3.ed. Rio de Janeiro: Jorge Zahar, 2003.

VERTOVEC, S.; COHEN, R. Introduction: Conceiving Cosmopolitanism. In: (eds). Conceiving cosmopolitanism: theory, context and practice Oxford: Oxford University Press, 2006. p. 1-22.

. Transnationalism. New York: Routledge, 2009.

WALLERSTEIN, I. El moderno sistema mundial. Cidade do México: Siglo Veinteuno Editores, 1979. 